\title{
BARLEY MUTANTS WITH DEFECTS IN PHOTOSYNTHETIC CARBON DIOXIDE FIXATION
}

\author{
by \\ BODIL CARLSEN \\ Department of Physiology, Carlsberg Laboratory, \\ DK-2500 Copenhagen, Valby \\ and \\ Institute of Genetics, University of Copenhagen, \\ Øster Farimagsgade 2A, DK-1353 Copenhagen K, Denmark
}

Key words: xantha mutants, viridis mutants, carbon reduction cycle, $\mathrm{CO}_{2}$ fixation in light and darkness

Carbon dioxide fixation by leaf pieces from 12 different chloroplast mutants and wild type barley has been analysed. In the light leaf pieces from wild type seedlings fixed ${ }^{14} \mathrm{CO}_{2}$ at a rate of approximately $80 \mu$ moles per gram fresh weight per hour, or $40 \mu$ moles per $\mathrm{mg}$ chlorophyll per hour. Fixation of ${ }^{14} \mathrm{CO}_{2}$ in darkness occurred at one to four per cent of the rate in light.

Five of the mutants investigated (vir-z $b^{63}, v i r-l^{27}, v i r-z d^{69}, v i r-c^{12}$ and $x a n-m^{3}$ ) were completely blocked in light-dependent $\mathrm{CO}_{2}$ fixation. The mutants vir- $m^{29}$, vir- $-u^{46}, x a n-d^{49}, x a n-c^{47}, v i r-t^{45}, x a n-t^{50}$ and vir- ${ }^{23}$ all yielded reduced photosynthetic rates on a gram fresh weight basis, but, with the exception of $v i r-k^{23}$, their photosynthetic rates on a chlorophyll basis differed by less than a factor of two from that of the wild type. On a chlorophyll basis vir- $k^{23}$ showed an enhanced rate of ${ }^{4} \mathrm{CO}_{2}$ fixation in comparison with the wild type.

Barley mutants lacking light-dependent ${ }^{14} \mathrm{CO}_{2}$ incorporation fixed in darkness or in light similar small amounts of ${ }^{14} \mathrm{CO}_{2}$ into malate, aspartate, glutamate and citrate as did the wild type in darkness. Photosynthetic products in the mutants capable of light-dependent $\mathrm{CO}_{2}$ fixation were qualitatively the same as in the wild type, and the patterns of distribution of tracer carbon gave no evidence of any defects in reactions following the fixation of $\mathrm{CO}_{2}$. The gross correlation between chlorophyll contents and photosynthetic rates on a chlorophyll basis among these mutants with the exception of vir- $k^{23}$ suggests that the reduced absorption of light by the lower amounts of chlorophyll in these mutants is the major or only factor responsible for their reduced photosynthetic rates on a gram fresh weight of leaf basis.

The suggestion is made that vir- $\mathbf{k}^{23}$, which is characterized by a far higher photosynthetic rate in bright light than the wild type on a chlorophyll basis, contains several-fold lower amounts of light-harvesting chlorophyll per photosynthetic unit than wild type, whereas the other mutants that are capable of photosynthesis have photosynthetic units of the same size as the wild type but fewer of them. 


\section{INTRODUCTION}

Photosynthetic carbon dioxide fixation is dependent on the production of ATP and reducing power in the form of NADPH in the chloroplast. Mutations leading to defects in light harvesting or the photosynthetic reaction centers, electron transport, photophosphorylation or in NADP reduction will all result in impaired $\mathrm{CO}_{2}$ assimilation. Finally the reduction or absence of $\mathrm{CO}_{2}$ fixation in mutants may result from defects in the carbon reduction cycle.

It was the purpose of this investigation to study the capacity of $\mathrm{CO}_{2}$ fixation in light and darkness by seedling leaves from a series of twelve barley mutants and to analyse the compounds into which carbon was fixed. The procedures developed by BENSON et al. (2) for studying the pathway of ${ }^{14} \mathrm{CO}_{2}$ assimilation were adapted for this analysis.

The twelve mutants represent mutations in twelve different nuclear genes (16). None of them survive to maturity under field conditions, and they were all selected originally for pigment deficiency at the seedling stage.

In seedlings of the mutants $x a n t h a-m^{3}$, viridis$c^{12}$, viridis- $l^{27}$, viridis- $z b^{63}$ and viridis- $z d^{69} \mathrm{HEN}$ NINGSEN et al. (6) could not detect oxygen evolution. It was of interest to determine if light dependent $\mathrm{CO}_{2}$ fixation, as expected, was absent in these mutants. Mutants xantha-c ${ }^{47}$ and xantha- $d^{49}$ contain giant grana and have aberrant lamellar protein composition $(15,7,11)$. The mutant xantha- $^{50}$ is characterized by an abnormally rapid esterification of its newly-formed chlorophyllide $(6,8)$ and viridis- $k^{23}$ is defective in chlorophyll biosynthesis, accumulating $\mathrm{Mg}$ protoporphyrin instead of protochlorophyllide upon supply of $\delta$-aminolevulinic acid to darkgrown seedlings. Mutants viridis- $m^{29}$, viridis- $u^{46}$ and viridis- $t^{45}$ were chosen because they contain reduced but substantial amounts of chlorophyll and evolve oxygen (6).

\section{MATERIALS AND METHODS}

\subsection{Plant Material}

For a short description of the barley mutant stocks used here (see listing in Table I) and their genetic backgrounds the reader is referred to VON WETTSTEIN \& KRISTIANSEN (16).

Seedlings were grown for 7 days in plastic trays filled with vermiculite and watered constantly from below with tap water in a growth champer with constant illumination (150 ft.c.) at $21^{\circ} \mathrm{C}$.

Since the barley mutants investigated here do not survive when grown in the field, the stocks are maintained in the heterozygous condition, and in all cases the progeny arising from a heterozygous plant showed a Mendelian segregation of three wild type to one mutant seedling. The homozygous mutants were identified by colour; they are all yellow or paler green than wild type barley.

\section{$2.2{ }^{14} \mathrm{CO}_{2}$ fixation}

The terminal $5 \mathrm{~cm}$ of primary leaves were cut with a razor blade into $1-2 \mathrm{~mm}$ pieces and mixed well before $0.5 \mathrm{~g}$ samples were weighed out, wrapped in aluminium foil and kept on ice until the experimental incubations. The leaf pieces were floated on $7.5 \mathrm{ml}$ buffer $(6 \mathrm{mM} \mathrm{NaHCO}$ with $75 \mu \mathrm{Ci} \mathrm{NaH}{ }^{14} \mathrm{CO}_{3}$ giving a specific activity of $1.6 \mu \mathrm{Ci} / \mu \mathrm{mole}$, and $50 \mathrm{mM} \mathrm{N}$-2-hydroxyethylpiperazine-2-ethane sulfonic acid (HEPES) buffer, $\mathrm{pH}$ 7.6) in stoppered Erlenmeyer flasks, which were shaken slowly in a water bath at $21^{\circ} \mathrm{C}$.

After incubation for $5 \mathrm{~min}$ in darkness where the flasks were wrapped in aluninium foil, the leaf pieces were allowed to fix ${ }^{14} \mathrm{CO}_{2}$ in bright light for 2 or $5 \mathrm{~min}$ (Philips HLRG 400W lamp) at a distance of $8 \mathrm{~cm}$ from the tip of the bulb. Alternatively, leaf segments were incubated for 7 or $10 \mathrm{~min}$ in darkness to provide the basis, by subtraction, for obtaining the light dependent, photosynthetic ${ }^{14} \mathrm{CO}_{2}$ fixation by leaf segments receiving bright light. Segments from wild type leaves were run in parallel with mutant segments in at least one experiment for each of the mutants and served as internal controls in most of the experiments. No more than two of the mutants were examined in any single experiment.

\footnotetext{
Abbreviation: fr.wt. - fresh weight, ft.c. - footcandles, UDP-glucose - uridine diphosphate glucose, xan - xantha, vir - viridis, chl. - chlorophyll
} 
The reactions were stopped by adding boiling methanol to give a final concentration of $80 \%$ methanol. After killing, the leaf material was ground with a mortar and pestle in the accompanying $80 \%$ methanol. After allowing the debris to settle, duplicate $100 \mu$ l aliquots were placed on glass fiber discs, $100 \mu \mathrm{IN} \mathrm{HCl}$ was added to each disc and the discs carefully dried and counted in a liquid scintillation counter (Tricarb Packard, model 2002) using Dimilume as scintillator.

\subsection{Chromatography}

For analysis of the radioactive compounds formed, the extracts were centrifuged and concentrated with a rotary evaporator to approximately $1 \mathrm{ml}$, and aliquots were spotted on Whatman No. 3 chromatographic paper. Two dimensional chromatography was carried out with water-saturated phenol containing $2 \mathrm{mM}$ ethylenediaminetetraacetic acid (EDTA) running in the first direction for 18 hours and equal volumes of n-butanol-water $(370: 25 \mathrm{v} / \mathrm{v})$ and propionic acid-water (180:220 v/v) running in the second direction for 11 hours $(2,12)$. For localization of the radioactive spots the chromatograms were placed on X-ray films (Ilford Rapid R) and exposed for 7 days. The spots were subsequently cut out from the chromatograms and counted directly in Dimilume, or where chromatograms were utilized for identification of the products, they were treated as detailed below.

\subsection{Identification of ${ }^{14} \mathrm{CO}_{2}$ products}

The autoradiograms of photosynthetic products resembled those previously published by JENSEN \& BASSHAM (9). The radioactive spots were cut out from a number of typical chromatograms and extracted individually with distilled water. Aliquots of extracts from single spots were co-chromatographed on Whatman No. 3 paper strips with authentic samples of the suspected compounds, using both solvent systems described above. Radioactive phosphate esters were first hydrolysed enzymatically by acid phosphatase and identified as the corresponding parent compound. The position of the radioactivity on the paper strips were located with a radiochromatogram scanner (Packard, model 7201), and standards were detected by colour after spraying the strips with suitable reagents.

The distribution of radioactivity in the various ${ }^{14} \mathrm{C}$ labelled products was determined by cutting out the spots and liquid scintillation counting without elution from the paper. No quenching by the paper was found in trial runs. In the cases where the extent of recovery of radioactivity applied to the chromatograms was examined it was found to be about $70 \%$.

\subsection{Chlorophyll analysis}

Chorophyll $\mathbf{a}$ and $\mathbf{b}$ were determined spectrophotometrically using the equations of ARNON (1) after extraction from samples of leaf tissue into aqueous $80 \%$ acetone in the presence of calcium carbonate.

\section{RESULTS AND DISCUSSION}

The analysed segments from primary leaves of the wild type seedlings contained approximately $1800 \mu \mathrm{g}$ chlorophyll per gram fr.wt. Under the same growth conditions all mutants examined had a reduced content of chlorophyll ranging from $69 \%$ to $11 \%$ of that found in the wild type. In table I the chlorophyll content is given for the individual mutants which are ordered by decreasing chlorophyll content. The chlorophyll $a / b$ ratios obtained for the mutants varied widely, a ratio of 3.2 being characteristic for the wild type (Table I). Six of the mutants $\left(v i r-m^{29}, v i r-u^{46}, x a n-d^{49}, x a n-c^{47}, v i r-z d^{69}\right.$ and $x a n-$ $m^{3}$ ) had ratios significantly below 3 , while four of the mutants (vir-c ${ }^{12}, v i r-p^{27}, v i r-z b^{63}$ and vir- $\left.k^{23}\right)$ had substantially higher chlorophyll a to chlorophyll $b$ ratios than the wild type.

In darkness all leaf pieces were able to fix small amounts of ${ }^{14} \mathrm{CO}_{2}$ estimated at 1 to $3 \mu \mathrm{mo}$ les $(\mathrm{g} f \mathrm{fr}, \mathrm{wt} .)^{-1}(\mathrm{hr})^{-1}$ based on 7 and 10 minute fication periods. This rate is somewhat but not significantly overestimated, because ${ }^{14} \mathrm{CO}_{2}$ incorporation in darkness begins with a rapid gulp and does not become linear with time until approximately 2 minutes after ${ }^{14} \mathrm{CO}_{2}$ is supplied in the present experimental system. The gulp is attributed to a step-up in the availability of $\mathrm{CO}_{2}$ shortly after time zero, which should give accelerated $\mathrm{CO}_{2}$ fixation and thereby lead to a de- 
cline in the original level of substrate for the carboxylation reaction to a new, lower steady state level. The substrate in question is presumably phosphoenolpyruvate (17). The rates of $\mathrm{CO}_{2}$ fixation in darkness by leaf pieces of vir$m^{29}, x a n-d^{49}, x a n-c^{47}, x a n-t^{50}$ and $x a n-m^{3}$ were only 50 to 70 per cent of the rates found for wild type leaf pieces, while the rates of ${ }^{14} \mathrm{CO}_{2}$ incorporation in darkness by leaf pieces from the other mutants did not differ from those obtained with wild type controls. The significance of the observed reduction in dark $\mathrm{CO}_{2}$ fixation capacity in some of the mutants is not known and no explanation is apparent.

In bright light wild type leaf pieces assimilated approximately $40 \mu$ moles $\mathrm{CO}_{2}(\mathrm{mg}$ chlorophyll $)^{-1}(\mathrm{hr})^{-1}$ or $80 \mu$ moles $\mathrm{CO}_{2}$ (g fr. wt. $)^{-1}(\mathrm{hr})^{-1}$ (Table I). Hourly photosynthetic rates calculated from ${ }^{14} \mathrm{CO}_{2}$ incorporation by wild type leaf pieces after 2 or 5 min photosynthesis were the same, and thus no lag in the assumption of steady state photosynthesis was detected. Table I shows further that with the mutants vir- $t^{-3}$ and vir- $k^{23}$ no lag was found, while

Table I

$14 \mathrm{CO}_{2}$ fixation in leaf pieces from wild type and mutant seedlings of barley.

The leaf pieces were incubated for $5 \mathrm{~min}$ in darkness and then illuminated for 2 or $5 \mathrm{~min}$, respectively. The values for light dependent $\mathrm{CO}_{2}$ fixation are corrected by subtracting the number of counts fixed in the dark over a 7 or $10 \mathrm{~min}$ period, respectively. (For wild type data standard deviations are given for 7 independent determinations; results for mutants represent the mean of two independent experiments with the exception of $x a n-a^{49}$, $\left.x a n-c^{n 7}, x a n-t^{30}\right)$.

\begin{tabular}{|c|c|c|c|c|c|}
\hline \multirow[b]{3}{*}{ Genotype } & & & \multicolumn{3}{|c|}{ Light-dependent $\mathrm{CO}_{2}$ fixation } \\
\hline & \multicolumn{2}{|l|}{ Chlorophyll } & \multirow{2}{*}{$\begin{array}{l}\text { Light } \\
(\min )\end{array}$} & \multirow{2}{*}{$\begin{array}{l}\mu \text { moles per } \\
\mathrm{g} \text { fr. Wt. hr }\end{array}$} & \multirow{2}{*}{$\begin{array}{c}\mu \text { moles per } \\
\text { mg chl.hr }\end{array}$} \\
\hline & $\mu \mathrm{g}$ per $\mathrm{g}$ fr.wt. & $\mathrm{a} / \mathrm{b}$ & & & \\
\hline wild type & $1840 \pm 110$ & 3.2 & $\begin{array}{l}2 \\
5\end{array}$ & $\begin{array}{l}78 \pm 4 \\
79 \pm 6\end{array}$ & $\begin{array}{l}42 \pm 3 \\
43 \pm 4\end{array}$ \\
\hline$v i r-m^{29}$ & 1260 & 2.3 & 2 & 45 & 36 \\
\hline$v i r-z b^{63}$ & 980 & 4.8 & $\begin{array}{l}2 \\
5\end{array}$ & 0 & $\begin{array}{r}43 \\
0\end{array}$ \\
\hline$v i r-t^{46}$ & 950 & 2.4 & $\begin{array}{l}2 \\
5\end{array}$ & $\begin{array}{l}14 \\
25\end{array}$ & $\begin{array}{l}15 \\
26\end{array}$ \\
\hline$x a n-a^{n g}$ & 670 & 2.1 & $\begin{array}{l}2 \\
5\end{array}$ & $\begin{array}{l}20 \\
37\end{array}$ & $\begin{array}{l}30 \\
55\end{array}$ \\
\hline$x a n-c^{A 7}$ & 610 & 2.2 & $\begin{array}{l}2 \\
5\end{array}$ & $\begin{array}{l}10 \\
14\end{array}$ & $\begin{array}{l}16 \\
23\end{array}$ \\
\hline vir-tss & 570 & 3.5 & $\begin{array}{l}2 \\
5\end{array}$ & $\begin{array}{l}23 \\
25\end{array}$ & $\begin{array}{l}44 \\
49\end{array}$ \\
\hline vir-/27 & 370 & 5.0 & $\begin{array}{l}2 \\
5\end{array}$ & $\begin{array}{l}0 \\
0\end{array}$ & $\begin{array}{l}0 \\
0\end{array}$ \\
\hline$v i r-z d^{s \theta}$ & 360 & 2.3 & $\begin{array}{l}2 \\
5\end{array}$ & $\begin{array}{l}0 \\
0\end{array}$ & $\begin{array}{l}0 \\
0\end{array}$ \\
\hline vir-c $c^{12}$ & 360 & 12 & $\begin{array}{l}2 \\
5\end{array}$ & $\begin{array}{l}0 \\
0\end{array}$ & $\begin{array}{l}0 \\
0\end{array}$ \\
\hline$x a n-t^{50}$ & 310 & 2.9 & $\begin{array}{l}2 \\
5\end{array}$ & $\begin{array}{l}4 \\
7\end{array}$ & $\begin{array}{l}12 \\
22\end{array}$ \\
\hline$v i r-k^{23}$ & 280 & 4.3 & $\begin{array}{l}2 \\
5\end{array}$ & $\begin{array}{l}53 \\
55\end{array}$ & $\begin{array}{l}185 \\
198\end{array}$ \\
\hline$x a n-m^{3}$ & 200 & 2.6 & $\begin{array}{l}2 \\
5\end{array}$ & $\begin{array}{l}0 \\
0\end{array}$ & $\begin{array}{l}0 \\
0\end{array}$ \\
\hline
\end{tabular}


$v i r-m^{29}, v i r-u^{46}, x a n-d^{49}, x a n-c^{47}$ and $x a n-t^{50}$ leaf pieces all gave lower photosynthetic rates over $2 \mathrm{~min}$ than over $5 \mathrm{~min}$ intervals, indicating a lag period before steady state photosynthesis was established.

HEBER \& WILLENBRINK (5) working with spinach leaves in ${ }^{14} \mathrm{CO}_{2}$ enriched air reported a lag phase of 1-2 min before a constant rate of ${ }^{14} \mathrm{CO}_{2}$ incorporation ensued after the onset of illumination. This observation matches the present results with leaf pieces from certain of the mutants as detailed above but not the results with leaf pieces from wild type barley or from vir-t ${ }^{45}$ and vir-k $k^{23}$. The discrepancy found between spinach and wild type barley may depend simply on differences in the experimental procedures employed. Spinach was provided with ${ }^{14} \mathrm{CO}_{2}$ in air, while barley was floating on a solution containing $\mathrm{NaH}^{14} \mathrm{CO}_{3}$ or rather the derivative ${ }^{14} \mathrm{C}$-containing species. There is no ready explanation for the lag in the onset of steady state photosynthesis in some of the mutants and not in others. The lag is not limited particularly to those giving the lower or higher photosynthetic rates.

Since the lag found with some of the mutants in the onset of steady state photosynthesis distorts the comparisons of hourly rates based on light dependent ${ }^{14} \mathrm{CO}_{2}$ fixation for 2 or $5 \mathrm{~min}$ in Table I, an atttempt was made to obtain hourly rates in which the lag played a lesser or no role. Hourly photosynthetic rates based on light dependent ${ }^{14} \mathrm{CO}_{2}$ fixation occurring in the interval between 2 and $5 \mathrm{~min}$ after the onset of illumina- tion were calculated and are presented in Table II. While there is no evidence that the lag, where present, was concluded after $2 \mathrm{~min}$ of light, its depressive effect on calculated hourly rates is certainly reduced, if not eliminated, by this procedure. A striking result is observed in Table II, only three of the mutants capable or photosynthesis show hourly light dependent ${ }^{14} \mathrm{CO}_{2}$ fixation rates on a chlorophyll basis that are lower than wild type barley. These are xan$c^{47}, x a n-t^{30}$ and $v i r-u^{46}$, whose photosynthetic capacities on a chlorophyll basis range from 64 to 79 per cent of the wild type. The mutants vir- $m^{29}$ and $v i r-t^{45}$ do not differ markedly from the wild type, while vir- $k^{23}$ and $x a n-d^{49}$ have higher hourly photosynthetic rates on a chlorophyll basis than does the wild type. The question arises whether $x a n-c^{47}, x a n-t^{50}$ and vir- $u^{46}$ really are characterized by lower photosynthetic capacity than that of wild type barley on a chlorophyll basis. If the lag preceding the assumption of steady state photosynthesis is substantially longer than 2 min in these mutants, they may very well be equal to the wild type in photosynthetic capacity. The mutant vir- $k^{23}$ stands out particularly from the others in that on a chlorophyll basis its photosynthetic rate is 3- to 6-fold higher than in the wild type. An attractive interpretation of this result is that light-harvesting chlorophyll in vir- $k^{23}$ is drastically reduced in comparison to the wild type, but sufficient to allow high photosynthetic rates in bright light, while the photosystems of the other mutants capable of photosynthesis contain ap-

Table II

Light-dependent $14_{\mathrm{CO}}$ fixation in the interval between 2 and 5 min after the onset of bright illumination. See legend of Table Ifor details. Data are given on an hourly basis.

\begin{tabular}{|c|c|c|c|c|}
\hline \multirow[b]{2}{*}{ Genotype } & \multicolumn{2}{|c|}{ per gram fresh weight } & \multicolumn{2}{|c|}{ per mg chlorophyll } \\
\hline & $\mu$ moles $\mathrm{CO}_{2}$ & $\%$ of wild type & $\mu$ moles $\mathrm{CO}_{2}$ & $\%$ of wild type \\
\hline wild type & 80 & 100 & 43 & 100 \\
\hline vir-m $m^{29}$ & 64 & 80 & 50 & 116 \\
\hline$v i r-u^{46}$ & 33 & 41 & 34 & 79 \\
\hline$x a n-d^{49}$ & 48 & 60 & 71 & 164 \\
\hline$x a n-c^{47}$ & 17 & 21 & 28 & 64 \\
\hline vir-tas & 27 & 33 & 50 & 116 \\
\hline$x a n-t^{50}$ & 9 & 11 & 28 & 64 \\
\hline$v i r-k^{23}$ & 58 & 72 & 204 & 492 \\
\hline
\end{tabular}


proximately the same number of light-harvesting chlorophylls as those of the wild type. Since the mutants have lower amounts of chlorophyll than the wild type, it follows that those with the same number of chlorophyll molecules per photosynthetic unit as the wild type must posses a smaller number of units per leaf area than does the wild type.

Polarographic studies with leaf pieces held on a bare platinum cathode have supplied data on oxygen evolution $(6,10)$ which complement the present data on $\mathrm{CO}_{2}$ fixation. Those mutants which are unable to carry out light dependent $\mathrm{CO}_{2}$ fixation, namely, vir-2 $b^{63}$, vir- $l^{27}$, $v i r-z d^{69}, v i r-c^{12}$ and $x a n-m^{3}$ (Table I) also do not evolve oxygen in bright light (6). The incorporation of ${ }^{14} \mathrm{CO}_{2}$ in these mutants is neither stimulated nor inhibited by light. This suggests that light has no direct influence on the carboxylation of phosphoenolpuruvate (17), which presumably is the reaction accounting for $\mathrm{CO}_{2}$ incorporation in darkness. TAMAS et al. (13)

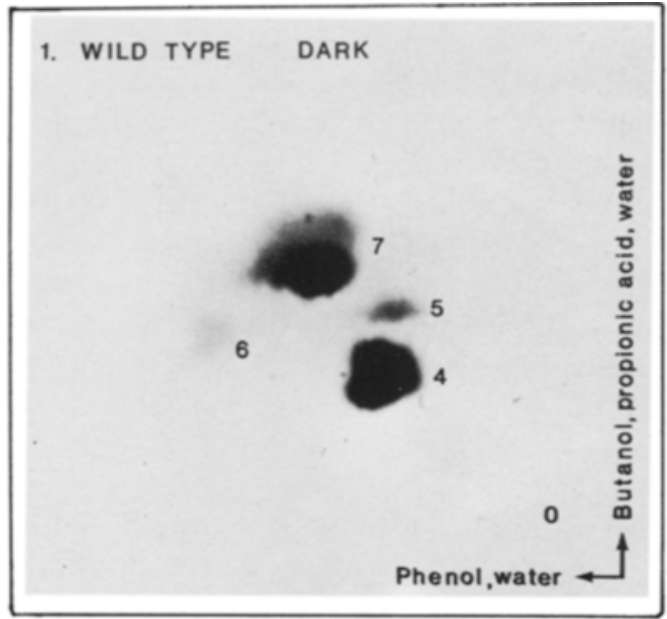

3. vir-c ${ }^{12}$ LIGHT

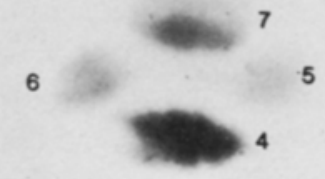

2. WILD TYPE LIGHT

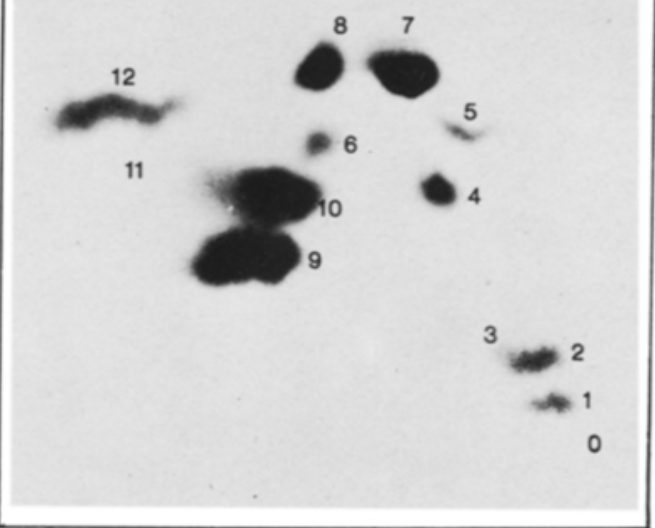

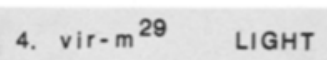

12
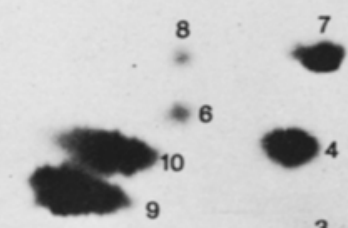

5

11

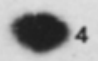

3

0

Figures 1-4: Autioradiograms of products of ${ }^{14} \mathrm{CO}_{2}$ fixation in leaf pieces. Products: 1, UDP-glucose; 2, glucose-6phosphate, fructose-6-phosphate and sedoheptulose-7-phosphate; 3, 3-phosphoglycerate; 4, aspartate; 5, citrate; 6 , glutamate; 7 , malate; 8 , glycerate; 9 , sucrose; 10 , serine and glycine; 11 , threonine; 12 , alanine; 13 , unidentified; $0=$ origin. Dark means $10 \mathrm{~min}$ incubation in darkness; light means $5 \mathrm{~min}$ in darkness followed by $5 \mathrm{~min}$ in bright light. 
have come to a similar conclusion earlier. The mutants that show lower photosynthetic activity than the wild type on a fresh weight basis (Table I) evolve oxygen in light (6), but at rates lower than the wild type (10) on a leaf area basis. Fresh weight and area bases are related by a constant, since leaves of the mutants do not differ morphologically from those of the wild type.

While none of the mutants included in this study survive as homozygotes in the field, all that have at least some capacity for photosynthesis (with the possible exception of $x a n-t^{30}$, which has not been tested) live longer in the laboratory under continous light than do mutants which are blocked completely for light dependent $\mathrm{CO}_{2}$ fixation. Representative mutants lacking photosynthesis (vir-zb $b^{63}$ and vir-zd $d^{69}$, cf. Table I) survive for 2 or 3 weeks in continuous light (150 ft.c.) at $22^{\circ} \mathrm{C}$, and this is also the survival period for the wild type seedlings grown in darkness at $22^{\circ} \mathrm{C}$. Seedlings of vir- $u^{46}$ and $x a n-c^{11}$ survived in continuous light for 6 to 10 weeks; vir-m ${ }^{29}, x a n-d^{49}$, vir- $t^{45}$ and $v i r-k^{23}$ lived longer than 13 weeks; vir- $m^{29}$ and vir- $t^{43}$ after being shifted to lower temperature and higher light intensity in later stages of growth produced viable seed, thus completing the life cycle, while $x a n-d^{49}$ and vir- $k^{23}$ under the same conditions died without having flowered. Photosynthetic capacity in the seedling stage on a gram fresh weight or chlorophyll basis does not correlate sufficiently with the subsequent growth of the mutants that photosynthesize to allow predictions concerning their survival. The mutant vir-t $t^{4 s}$, which was by far the more successful in growth and seed production in the laboratory, would have received one of the poorer prognoses. Perhaps under a different set of conditions, vir- $t^{45}$ and vir- $m^{29}$ would have been less successful and other mutants which failed to survive to maturity would have been more successful.

The major products of ${ }^{14} \mathrm{CO}_{2}$ fixation in darkness and intense light by leaf pieces of wild type and mutant barley have been analysed by autoradiography. Some typical autoradiographs are reproduced in Figures 1-5. The mutant vir- $c^{12}$ is selected here as exemplary of the group which lacked light-dependent $\mathrm{CO}_{2}$ fixation completely and included also $x a n-m^{3}, v i r-l^{27}, v i r-z b^{63}$ and vir- $z d^{69}$. Autoradiographs of the products of $\mathrm{CO}_{2}$ fixation in darkness or light by leaf pieces from all the mutants in this group were indistinguishable from one another and also from autoradiographs of the products of $\mathrm{CO}_{2}$ fixation in darkness by leaf pieces from the wild type or the mutants capable of photosynthesis. Figures 1 and 3 are included to illustrate a portion of these results. In the cases of non-photosynthetic $\mathrm{CO}_{2}$ fixation that were analysed quantitatively, aspartate accounted for 55 to 60 per cent of the ${ }^{14} \mathrm{C}$ fixed, malate for 30 to 35 per cent, and the remaining $10 \%$ of the label was split evenly between citrate and glutamate (see presentation of quantitative results that follows and Table III). Occasionally, autoradiography showed weak labelling also of alanine, glycerate

$$
\text { 5. vir-u } u^{46} \text { LIGHT }
$$

13

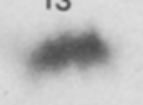

13

8

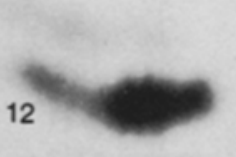

11

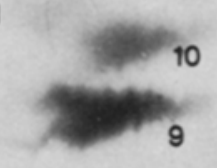

6

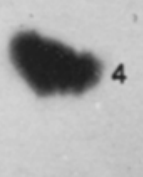

3

2

1

Figure 5: Autoradiogram of products of ${ }^{14} \mathrm{CO}_{2}$ fixation in leaf pieces of mutant viridis- $u^{46}$ in light. For explanations see under figures 1-4. 
and succinate, but the appearance of spots representing these compounds was sporadic, and these products were not quantitated.

No qualitative differences among the products of ${ }^{14} \mathrm{CO}_{2}$ fixation in bright light by leaf pieces of wild type barley and the mutants capable of photosynthesis were detected. Autoradiographs of the products synthesized in light by leaf pieces of wild type (Fig. 2); vir- ${ }^{29}$, a mutant with high photosynthetic capacity (Fig. 4); and vir- $u^{46}$, a mutant with more diminished photosynthetic ability (Fig. 5) illustrate the similarities of the patterns obtained.

Quantitative determinations on the distribution of radioactivity in the products of ${ }^{14} \mathrm{CO}_{2}$ fixation are summarized in Table III. To facilita-

Table III

Distribution of ${ }^{14} \mathrm{CO}_{2}$ among the products of $\mathrm{CO}_{2}$ fixation. See text for methods and calculation of results. Products labelled in darkness and in light (per cent of total radioactivity recovered in these products)

\begin{tabular}{|c|c|c|c|c|c|c|c|}
\hline \multirow[b]{2}{*}{ Compound } & \multirow[b]{2}{*}{ wild type } & \multicolumn{4}{|c|}{ Labelling during 10 min darkness } & \multirow[b]{2}{*}{$v i r-k^{23}$} & \multirow[b]{2}{*}{ vir-c $c^{12}$} \\
\hline & & vir-m $m^{29}$ & vir- $-u^{46}$ & $x a n-d^{4} g$ & $x a n-c^{47}$ & & \\
\hline $\begin{array}{l}\text { aspartate } \\
\text { citrate } \\
\text { glutamate } \\
\text { malate }\end{array}$ & $\begin{array}{r}56 \\
5 \\
5 \\
34\end{array}$ & $\begin{array}{r}60 \\
4 \\
5 \\
31\end{array}$ & & & & & $\begin{array}{r}57 \\
5 \\
5 \\
33\end{array}$ \\
\hline total cpm & 1995 & 1085 & & & & & 1646 \\
\hline
\end{tabular}

\begin{tabular}{|c|c|c|c|c|c|c|c|}
\hline Compound & wild type & $\begin{array}{l}\text { Labellir } \\
\text { vir- } m^{29}\end{array}$ & $\begin{array}{l}\text { ring } 5 \mathrm{n} \\
v i r-u^{46}\end{array}$ & $\begin{array}{r}\text { arkness } \\
x a n-d^{\mu 9}\end{array}$ & $\begin{array}{l}5 \text { min ligh } \\
x a n-c^{47}\end{array}$ & $v i r-k^{23}$ & $v i r-c^{12}$ \\
\hline $\begin{array}{l}\text { aspartate } \\
\text { citrate } \\
\text { glumate } \\
\text { malate }\end{array}$ & $\begin{array}{r}17 \\
6 \\
17 \\
61\end{array}$ & $\begin{array}{r}45 \\
5 \\
10 \\
40\end{array}$ & $\begin{array}{r}58 \\
3 \\
7 \\
32\end{array}$ & $\begin{array}{r}47 \\
3 \\
10 \\
40\end{array}$ & $\begin{array}{r}56 \\
3 \\
5 \\
36\end{array}$ & $\begin{array}{r}39 \\
6 \\
11 \\
44\end{array}$ & $\begin{array}{r}59 \\
5 \\
4 \\
32\end{array}$ \\
\hline total cpm & 4919 & 3868 & 2133 & 3891 & 2258 & 3466 & 1475 \\
\hline
\end{tabular}

\section{Table III (continued)}

Products labelled in light only (per cent of total radioactivity recovered in these products after incorporation of ${ }^{14} \mathrm{CO}_{2}$ for $5 \mathrm{~min}$ in darkness plus $5 \mathrm{~min}$ in light).

\begin{tabular}{l|r|r|r|r|r|r|r}
\hline Compound & wild type & vir-m ${ }^{29}$ & $v i r-u^{46}$ & xan- $d^{49}$ & xan-c & vir- $k^{23}$ & $v i r-c^{12}$ \\
\hline UDP-glucose & & & & & & & \\
and phosphate & & & & & & & \\
esters & 5 & 5 & 9 & 9 & 7 & 6 & - \\
glycerate & 15 & 5 & 3 & 1 & 3 & 8 & - \\
sucrose & 28 & 32 & 23 & 29 & 26 & 25 & - \\
serine and & 24 & 26 & 12 & 20 & 15 & 23 & - \\
glycine & 1 & 5 & 7 & 6 & 2 & 5 & - \\
threonine & 17 & 16 & 36 & 34 & 25 & 27 & - \\
alanine & 10 & 11 & 10 & 1 & 23 & 6 & - \\
unidentified & 22404 & 14700 & 4748 & 9079 & 3531 & 15983 & 0 \\
\hline total cpm & & & &
\end{tabular}


te comparisons the products are divided into two groups in the table, namely a group comprising those products which become labelled only in light and a second group comprising the products that become labelled in darkness or light. For normalization, the data from each of the chromatograms were treated in the following way: the fraction of the total recovered label found in each of the 13 radioactive spots was calculated and multiplied by the cpm fixed by $1 /$ 375 part of the leaf sample. The normalized cpm distributed among the products comprising each of the aforementioned two groups were summed separately and appear in Table III as total cpm. The distribution of label among the products within each group was then calculated as per cent of total cpm found in each product of the group.

In considering the products that become labelled either in darkness or light, two salient results emerge. Firstly, light stimulated ${ }^{14} \mathrm{C}$ incorporation into the group of products comprising aspartate, malate, citrate and glutamate was well over 2-fold in leaf pieces of vir- $m^{29}$ and wild type barley. Secondly, in wild type leaf pieces the distribution of label among these products depends on whether ${ }^{14} \mathrm{CO}_{2}$ is incorporated in light or in darkness; light diminished strongly the fraction of label in aspartate and enhanced the fractions of label in malate and glutamate in three separate experiments. The same trend is apparent also for vir- $m^{29}$. Stimulation of counts in citrate, glutamate and malate by light ranged from circa 3 to 8-fold in leaf pieces of vir- $m^{29}$ and wild type leaves, while light stimulation of ${ }^{14} \mathrm{C}$ incorporation into aspartatte was circa 3fold in $v i r-m^{29}$ and did not occur in wild type leaf pieces. No quantitation of ${ }^{14} \mathrm{C}$ products following $\mathrm{CO}_{2}$ incorporation in darkness by leaf pieces of vir- $u^{46}$, xan-c $c^{47}$ and vir- $k^{23}$ was undertaken. Nevertheless, with the reasonable assumption that such results would not differ from those obtained with leaf pieces of vir- $m^{29}$, vir-c ${ }^{12}$ and wild type barley after ${ }^{14} \mathrm{CO}_{2}$ fixation in darkness, a further conclusion can be drawn. Light seems to stimulate ${ }^{14} \mathrm{C}$ incorporation into the products under discussion by $x a n-d^{49}$ and $v i r-k^{23}$ leaf pieces in the same manner as in vir- $m^{29}$ leaf pieces. On the other hand, leaf pieces from the mutants vir- $u^{46}$ and $x a n-c^{47}$ behave in light like leaf pieces of wild type in darkness with regard to these products. It should be recalled that the mutants vir- $m^{29}$, xan- $d^{29}$ and vir- $k^{23}$ have relatively high photosynthetic capacity, while the mutants vir $-u^{46}$ and $x a n-c^{17}$ have low photosynthetic ability. The simplest explanation of these results is that the stimulation by light of the labelling of aspartate, citrate, glutamate and malate is tightly associated with moderate or high levels of photosynthesis and does not operate through some special, unknown pathway. The same conclusion was reached by TAMẢs et al. (13) on other grounds.

The failure of light to stimulate labelling of aspartate in leaf pieces of wild type barley (Table III) can perhaps be explained by a suggestion of GRAHAM and WALKER (4). The higher level of reduced pyridine nucleotides resulting from photosynthesis would favor the reduction of oxaloacetate, a common precursor of aspartate and malate, to malate and also drive the transamination of aspartate. Promoting these reactions would diminish the relative labelling of aspartate.

While the ratio of label in aspartate to label in malate was 1.6 , when ${ }^{14} \mathrm{C}$ incorporation took place in wild type leaf pieces in darkness, the ratio was 0.27 , when ${ }^{14} \mathrm{CO}_{2}$ fixation occurred for 5 minutes in darkness plus 5 minutes in light (Table III). The comparable ratios found for vir- $m^{29}$ were 1.9 and 1.1 , respectively. The low ratio of aspartate to malate labelling found in the wild type after ${ }^{14} \mathrm{CO}_{2}$ fixation during an interval that concluded with a light period is not supported by some of the earlier studies using whole leaves or leaf pieces $(3,14)$, but is in line with work by GRAHAM and WALKER (4) and TAMẢS et al. (1). The experimental systems cited in the above work are sufficiently different from the present one to make it difficult to determine whether results should be comparable.

Sucrose, serine, glycine and alanine accounted for 70 to 85 per cent of the tracer carbon that was incorporated into products that become labelled only in light in leaf pieces of wild type barley and all of the mutants capable of photosynthesis, and amino acids contained 40 to 60 per cent of the label. Thus, no gross quantitative differences in the patterns of these products of photosynthesis differentiated the 
various mutants and wild type. Certain differences in the incorporation of ${ }^{14} \mathrm{C}$ into these and other products that become labelled only in light are apparent in Table III, but no detailed interpretation is offered here, because the reproducibility of the individual data has not been ascertained.

Some general observations concerning the present findings can be made. Mutants with varying levels of chlorophyll deficiency and ability or inability to evolve oxygen in light were selected for this study. Those that are totally defective in oxygen-evolving capacity are also totally defective in light-dependent $\mathrm{CO}_{2}$ fixation. This is a reassuring result which indicates that, at least in these mutants, no alternative compound to water serves as electron donor for photosynthesis which went undetected by oxygen measurements. For the mutants with varying photosynthetic capacities the following generalizations emerge: 1) The products of photosynthesis on a fresh weight basis seem to be reduced in amount and not in kind; 2) with the exception of vir- $k^{23}$, a special case which has been discussed earlier, chlorophyll content is a good predictor (to better than a factor of 2) of the capacity for photosynthetic $\mathrm{CO}_{2}$ incorporation; 3 ) therefore it is likely that all of these mutants have lower photosynthetic rates than wild type barley on a gram fresh weight basis mainly or solely because of reduced light absorption, and accordingly none have a genetic lesion affecting the biochemistry of photosynthesis. In view of these conclusions it is not easy to explain why seedlings of the majority of the mutants which are active photosynthetically fail to survive under field or favorable laboratory conditions. The present study indicates that their photosynthetic capacities exceed those which might be thought sufficient for plant maintenance and perhaps for growth. A possibility, which has not been tested, is that the photosynthetic capacities of the mutants which die before maturity decline with increasing age to rates lower than the compensation point.

The postulation that the mutants with some, but reduced photosynthetic capability on a gram fresh weight basis are normal except for the primary process of light absorption leads to the surmise that the biochemical activities of their chloroplasts in vitro should be normal on a chlorophyll basis. In preliminary experiments this expectation has not been met, and the reasons are being sought.

\section{ACKNOWLEDGEMENTS}

I thank Drs. Albert KaHn and Gamini C. KanNangara and Professors KNUD W. HENNINGSEN and Diter von WeTtSTEIN for their invaluable advice and help during this investigation. Financial support by grant GM22051 of the USPHS National Institutes of Health to Professor D. vON WETTSTEIN is gratefully acknowledged.

\section{REFERENCES}

1. ARnon, D. I.: Copper enzymes in isolated chloroplasts. Polyphenoloxidase in Beta vulgaris. Plant Physiol. 24, 1-15 (1949)

2. Benson, A. A., J. A. Bassham, M. Calvin, T. C. Goodale, V. A. HaAs \& W. Stepka: The path of carbon in photosynthesis. V. Paper chromatography and radioautography of the products. $J$. Am. Chem. Soc. 72, 1710-1718 (1950)

3. Gee, R., G. Joshi, R. F. Bils \& P. Saltman: Light and dark $\mathrm{C}^{14} \mathrm{O}_{2}$ fixation by spinach leaf systems. Plant Physiol. 40, 89-96 (1965)

4. Graham, D. \& D. A. Walker: Some effects of light on the interconversion of metabolites in green leaves. Biochem. J. 82, 554-560 (1962)

5. Heber, U. \& J. Willenbrink: Sites of synthesis and transport of photosynthesis products within the leaf cell, Biochim. Biophys. Acta 82, 313-324 (1964)

6. Henningsen, K. W., J. E. Boynton, D. von WetTSTEIN \& N. K. Boardman: Nuclear genes controlling chloroplast development in barley. In "The Biochemistry of Gene Expression in Higher Organisms". Pollak, J. K. and J. W. Lee eds., Australian and New Zealand Book Company. pp 457-478 (1973)

7. Henningsen, K. W., N. C. Nielsen \& R. M. SMILLIE: The effect of nuclear mutations on the assembly of photosynthetic membranes in barley. Portugal. Acta Biol. Ser. A. XIV, 323-344 (1974)

8. Henningsen, K. W. \& S. W. Tyorne: Esterification and spectral shifts of chlorophyll(ide) in wildtype and mutant seedlings developed in darkness. Physiol. Plant 30, 82-89 (1974)

9. Jensen, R, G. \& J. A. Bassham: Photosynthesis by isolated chloroplasts. Proc. Nat. Acad. Sci. USA 56, 1095-1101 (1966) 
10. KAHN, A. \& B. CARLSEN: Evaluation of the photosynthetic capacity of leaves using the oxygen rate electrode. Abstract. VIII. Internat. Congr. Photobiol. Aug. 29th - Sept. 3rd, P 56 (1976)

11. Nielsen, N. C., K. W. Henningsen \& R. M. SMILLIE: Chloroplast membrane proteins in wildtype and mutant barley. In "Proceedings of the Third International Congress on Photosynthesis". M. Avron ed., Elsevier Scientific Publ. Co., Amsterdam. pp 1603-1614 (1975)

12. Pedersen, T. A., M. Kirk \& J. A. Bassham: Light-dark transients in levels of intermediate compounds during photosynthesis in airadapted Chlorella. Physiol. Plant. 19, 219-231 (1966)

13. Tamas, I. A., E. W. Yemm \& R. G. S. Bidwell: The development of photosynthesis in darkgrown barley leaves upon illumination. Canad. J. Bot. 48, 2313-2317 (1970)
14. Tolbert, N. E. \& F. B. Gailey: Carbon dioxide fixation by etiolated plants after exposure to white light. Plant Physiol. 30, 491-499 (1955)

15. Wettstein, D. von, K. W. Henningsen, J. E. Boynton, G. C. Kannangara \& O. F. Nielsen: The genic control of chloroplast development in barley. In "Autonomy and Biogenesis of Mitochondria and Chloroplasts". N. K. Boardman, A. W. Linnane and R. M. Smillie eds., NorthHolland, Amsterdam. pp 205-223 (1971)

16. Wettstein, D. vON \& K. Kristiansen: Stock list for nuclear gene mutants affecting the chloroplast. Barley Genetics Newsletter 3, 113-117 (1973)

17. ZeLitch, 1.: Photosynthesis, Photorespiration and Plant Productivity. Academic Press, New York. pp 107-112 (1971) 